\title{
Farklı Ebatlardaki Kutular için Endüstri 4.0 Uyumlu Bir Otomatik Depolama ve Boşaltma Sistem (ODBS) Tasarımı
}

\author{
*1,2Uğur Koyun, ${ }^{3}$ Damla Özsoy ve ${ }^{4} \mathrm{H}$. Metin Ertunç \\ ${ }^{1}$ ROBO Otomasyon, Ar-Ge Departmanı, Kocaeli, Türkiye \\ ${ }^{2}$ Mühendislik Fakültesi, Bilgisayar Mühendisliği Bölümü Kocaeli Üniversitesi, Kocaeli, Türkiye \\ ${ }^{3}$ ROBO Otomasyon, Ar-Ge Departmanı, Kocaeli, Türkiye \\ ${ }^{4}$ Mühendislik Fakültesi, Mekatronik Mühendisliği Bölümü Kocaeli Üniversitesi, Kocaeli, Türkiye
}

\begin{abstract}
Özet
Günümüz teknolojisinde Endüstri 4.0 ile insan gücüne olan ihtiyaç azalmakta ve akıllı sistemlerin kullanımı her geçen gün artmaktadır. Bu gelişmelerden endüstriyel depolama sistemleri de etkilenmiş ve bunun sonucunda mekandan, zamandan ve insan gücünden tasarruf sağlayan farklı tipte Otomatik Depolama ve Boşaltma Sistemleri (ODBS) geliştirilmiştir. Bu sistemlerde ürünler, tek tip kutu veya farklı tip kutuların büyük bir kutuda birleştirilmesi biçiminde depolanmak üzere tasarlanmıştır. Bu bildiri kapsamında yapılan çalışmada, farklı tipteki kutulara herhangi bir müdahalede bulunmadan raflara yerleştirilebilmesi sağlanmış ve böylelikle kutu boyutundan bağımsız, ancak alt ve üst sınır kısıtlaması ile esnek bir ODBS modeli geliştirilmiş ve uygulaması yapılmıştır. Kutuların hacim ve ağırlıkları sensörler ile ölçülmüş ve bu ölçülen sensör verilerine göre yönlendirilen mekanik yapı, kutunun sistemde ilerleyebilmesi için uygun şekilde tasarlanmıştır. Çalışma sonucunda, geliştirilen sistemin uygulaması büyük ölçekte imalat yapan bir endüstriyel firmada başarıyla gerçekleştirilmiş ve sistem verimliliğini artırdığı gözlenmiştir.
\end{abstract}

Anahtar kelimeler: Endüstri 4.0, Otomatik Depolama ve Boşaltma Sistemleri (ODBS), sistem tasarım1.

\section{An Industry 4.0 Compatible Automatic Storage and Retrieval System (ASRS) Design for Boxes of Different Sizes}

\begin{abstract}
With Industry 4.0 in today's technology, the need for manpower decreases and the use of smart systems increases day by day. Large storage systems in huge manufacturing companies have also been affected by these developments. Although there are many types of them, these storage systems are called as Automatic Storage and Retrieval Systems (ASRS) and they save space, time and manpower where they are used. In these systems, products are designed to be stored in a single type box or combination of type boxes in a large box. In this paper, it was provided to be placed on shelves without being found in different types of boxes in the market, and thus, a flexible ASRS model content and application was made independent of the box size, but with lower and upper limit restrictions. The volumes and weights of the boxes have been measured by sensors, and the mechanical structure guided by this measured sensor can be programmed appropriately for the box to move through the system. To evaluate the performance of the developed system in this work, it was applied in a big manufacturing company that employs numerous and various sizes production materials and it was observed that the designed ASRS has increased the productivity of the company.
\end{abstract}

Key words: Industry 4.0, Automatic Storage and Retrieval System (ASRS), system design.

*Sorumlu Yazar: Adres: Karaköprü Mahallesi Atatürk Bulvarı No:410/A, ROBO Otomasyon, Gölcük/Kocaeli/Türkiye. E-posta: ugur.koyun@ robo.com.tr, Gsm: +905375527011 


\section{Giriş}

Firmalar depolama ihtiyacının artması ile depo alanlarını genişletmekte ve çalışan forklift sayısını arttırmaktadırlar. Bu genişleme depo alanı içerisinde yoğun bir trafik ve kontrol edilmesi zor bir depolama alanına sebep olur. Bu durumun engellenmesi ve artan rekabet şartlarına ayak uydurabilmek için firmalar Otomatik Depolama ve Boşaltma Sistemlerini (ODBS) tercih etmektedir [1].

ODBS sistemleri depolama işlemlerinin insan gücünden bağımsız ve aynı verimlilikte çalışmasını çok küçük ve ergonomik biçimde sağlamak amacıyla tasarlanmaktadır. Tasarlanan sistemler sektörlere göre farklılık göstermektedir. $\mathrm{Bu}$ farklılığın sebebi depolanan ürünlerin içeriği, paketlenme şekli, hacmi, ağırlığı, çeşidi ve adedi gibi özelliklerinin farklı olmasıdır. Ürünlerdeki bu farklılık ODBS sistemlerini de etkilemiş ve sonuçta kurulum tiplerine göre birbirlerinden ayrılan sistemler geliştirilmiştir. Mini depolama, çok derinlikli depolama, birim depolama ve operatör eli ile yapılan depolama ODBS'nin kurulum tipleridir [2]. ODBS sistemleri üzerine yapılmış uluslararası çalışmalar incelendiğinde zaman optimizasyonu üzerinde daha çok durulduğu gözlenmiştir [3,4].

ODBS sistemleri incelendiğinde ürünlerin depolanma şekli standart bir ebatta, tepsi üzerinde toplama ve farklı ebatlarda depolanabilir olmak üzere ayrılmaktadır. Standart ebatlı sistemlerde firmalar ihtiyacını karşılayan bir ebat seçmekte ve ODBS sisteminin ana parçaları olan konveyörler, yükleme robotları, boşaltma robotları ve raf yapılarını bu ebat için tasarlamaktadırlar. Bu sistemlerin dezavantajı, farklı ebattaki ürünleri depolayamamasıdır.

Tepsi üzerinde toplama sistemlerinde, aynı veya farklı ebat ve içerikteki ürünler, tek bir tepsi üzerinde toplanır ve depolanır. ODBS sisteminin tüm bölümleri tepsiyi sistem içerisinde taşıyacak şekilde tasarlanır. Bu sistem robotların daha az çalışıp daha fazla miktarda ürün depolamasına olanak sağlamaktadır. Bunun yanında bu sistemin dezavantajı, ürünlerin beraber depolanmasıdır. İstenen ürüne ulaşmak için ilgili tepsi raflardan indirilir; daha sonrasında ürün tepsiden alınır ve tepsi tekrar sisteme yüklenir.

Farklı ebatların depolandığı sistemlerde, kutu ebatları farklı olmakla birlikte her ebada ait bir raf hücresi bulunmaktadır. Bu sistemlerde ODBS bileşenleri dinamik bir yapıda tasarlanır ve sisteme yüklenen ürünlere göre çalışma şekilleri değişiklik gösterir. Bu tarz sistemlerde öncelikle ürünlerin ebatları ve ağırlıkları ölçülür. Ebat ve ağırlık ölçümü sonrasında ürün için en uygun raf hücresi tespit edilir. Ürün hücreye taşınırken konveyörler ve taşıma robotları ürünün ebadına göre ürünü mengene kolları ile referans konumda tutarlar. Böylelikle ürün konumu her pozisyonda hesaplanabilir ve takip edilebilirdir.

\section{Yöntem}

Farklı ebattaki ürünlerin ODBS sistemine uygun bir şekilde yüklenebilmesi ve boşaltılabilmesi için birtakım iş paketlerinin sırası ile yapılması gerekmektedir. Bu iş paketleri ve sırası Şekil 1'de gösterilmektedir. 


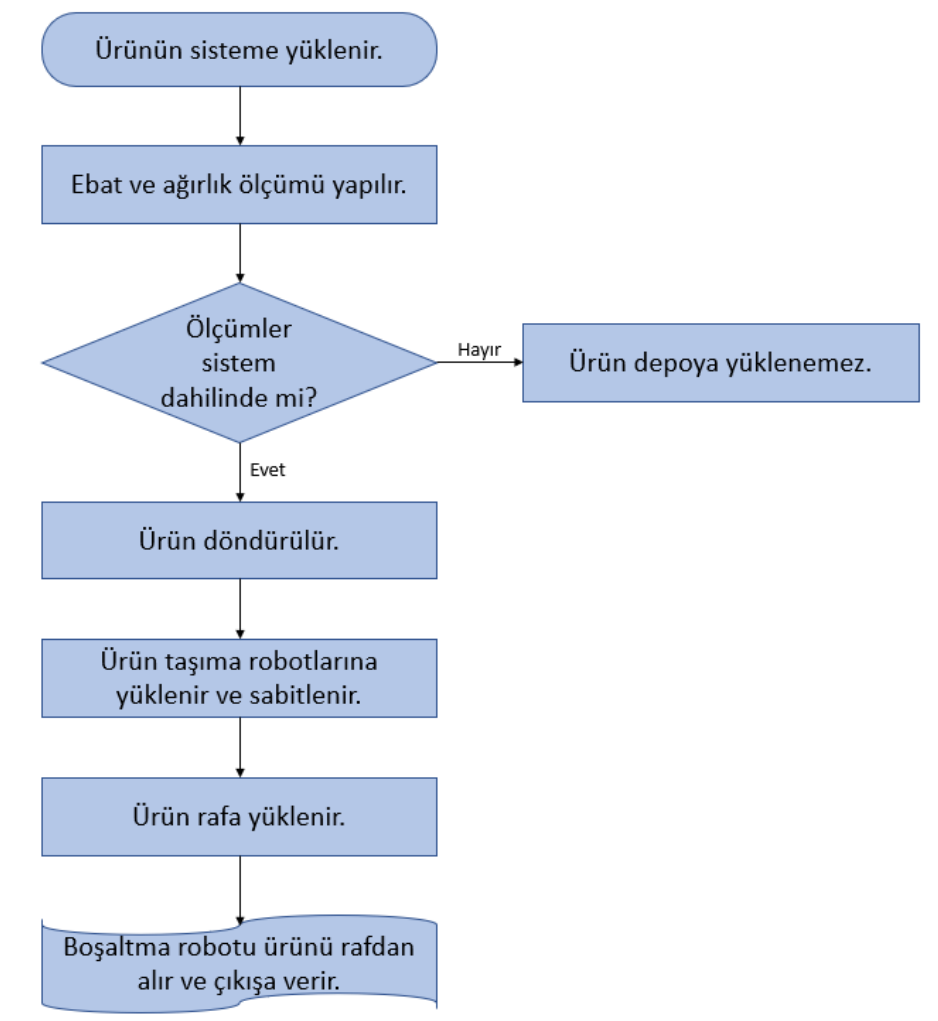

Şekil 1. Gerçekleştirilen iş paketleri

\section{1. Ürünün Sisteme Yüklenmesi}

Ürünler sistem girişinde operatör tarafından konumlandırılır. Konumlandırma sonrasında çiftel buton paneli kullanılarak ürünlerin sisteme girişi yapılır. Sistem girişinde konumlandırılan ürünlerin bir sonraki sensör panelinden doğrusal şekilde geçebilmesi için ürünler havalı pistonlar kullanılarak mengene kolları ile merkez pozisyona getirilir. Bu çalışma, Şekil 2'de gösterilmiş̧ir.

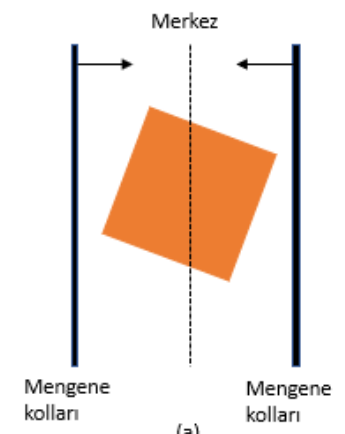

(a)

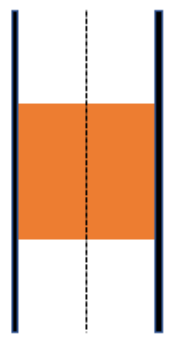

(b)

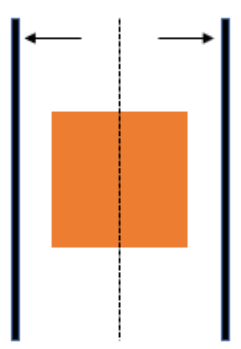

(c)

Şekil 2. Ürünleri merkez pozisyona getirilmesi (a) Ürünlerin sisteme yüklenmesi ve Mengene kollarının sıkıştırması (b) Ürünün pozisyonlanması (c) Mengene kollarının geri çekilmesi 


\subsection{Ebat ve Ağırlık Ölçümü}

Ebat ölçümü için kızılötesi hacim ölçer sensörler kullanılmıştır. Ürünlerin konveyörlerden ilerlemesi sırasında kızılötesi sensörler ürünlerin 3 farklı boyutunu ölçebilir şekilde dizilmiştir. Bu dizilim Şekil 3’te gösterilmiştir.

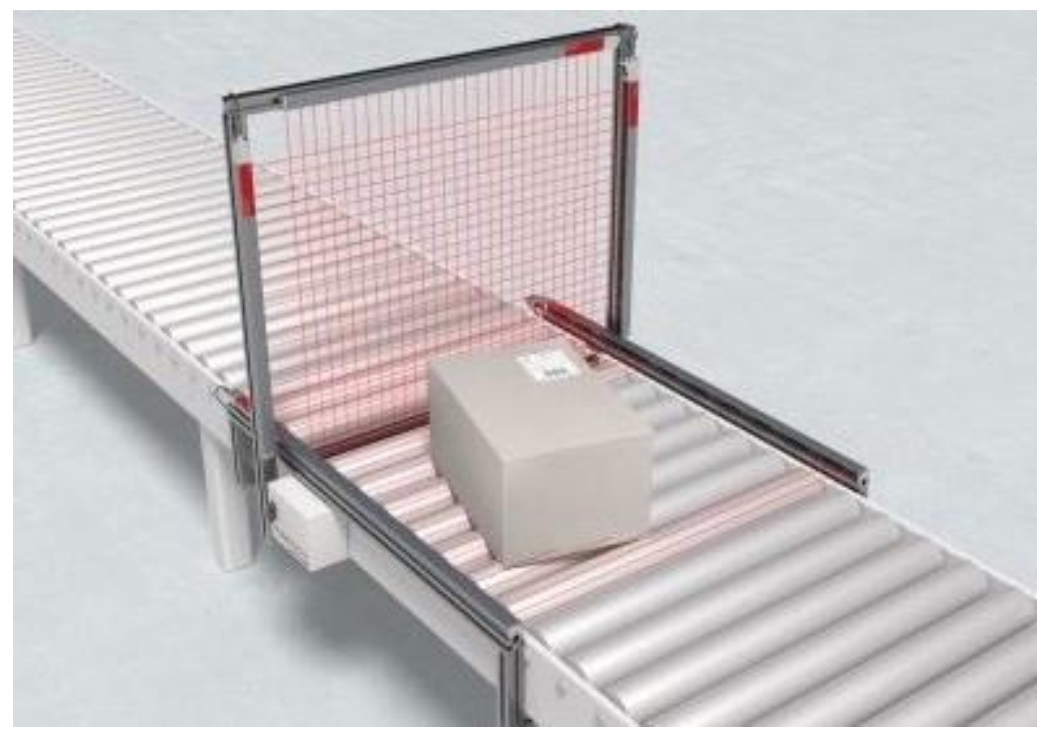

Şekil 3. Kızılötesi hacim ölçer sensörlerinin dizilimi

Ürünler hacim ölçüm paneli sonrasında cisim algılayıcı sensörlerin görüş alanına girerler ve konveyörler durdurulur. Ürünün durduğu konveyör bölgesinin alt kısmına ağırlık ölçüm sensörleri (loadcell) yerleştirilmiştir. Ağırlık ölçümünün tamamlanması ile PLC modülleri ağırlık ve hacim bilgilerini MES (Manufacturing Execution System) yazilımına OPC (Open Platform Communications) teknolojisini kullanarak iletirler [5,6]. MES yazılımı ölçüm değerlerini kontrol ederek ürünün sisteme dahil edilip edilemeyeceğine karar vermektedir.

\section{3. Ürün Döndürme}

Yapılan çalışmada çok derinlikli ODBS sistemi tasarlanmış ve raf hücrelerine eğim verilmiştir. Amaç hücrelere yerleştirilen ürünlerin yerçekimi etkisi ile hücrenin son noktasına kaymasıdır. Hücrelere yerleştirilen ürünlerin hafif olması ürünlerin hava ile oluşan sürtünme kuvvetini yenip kaymasını zorlaştırmaktadır. Ürünlerin hücrede kolayca ilerlemesini sağlamak amacıyla ürünlerin hücrelere kısa kenarı önde olacak şekilde girişi yapılmaktadır. Böylece ürünler hücrede kayarken daha az hava sürtünmesine maruz kalmakta ve ivmelenmesi daha kolay olmaktadır. Döndürme panelinin çalışma mantığı Şekil 4'te gösterilmektedir. Döndürülen ürünler pnömatik yapılar kullanılarak kartezyen taşıma robotları üzerine taşınır. 


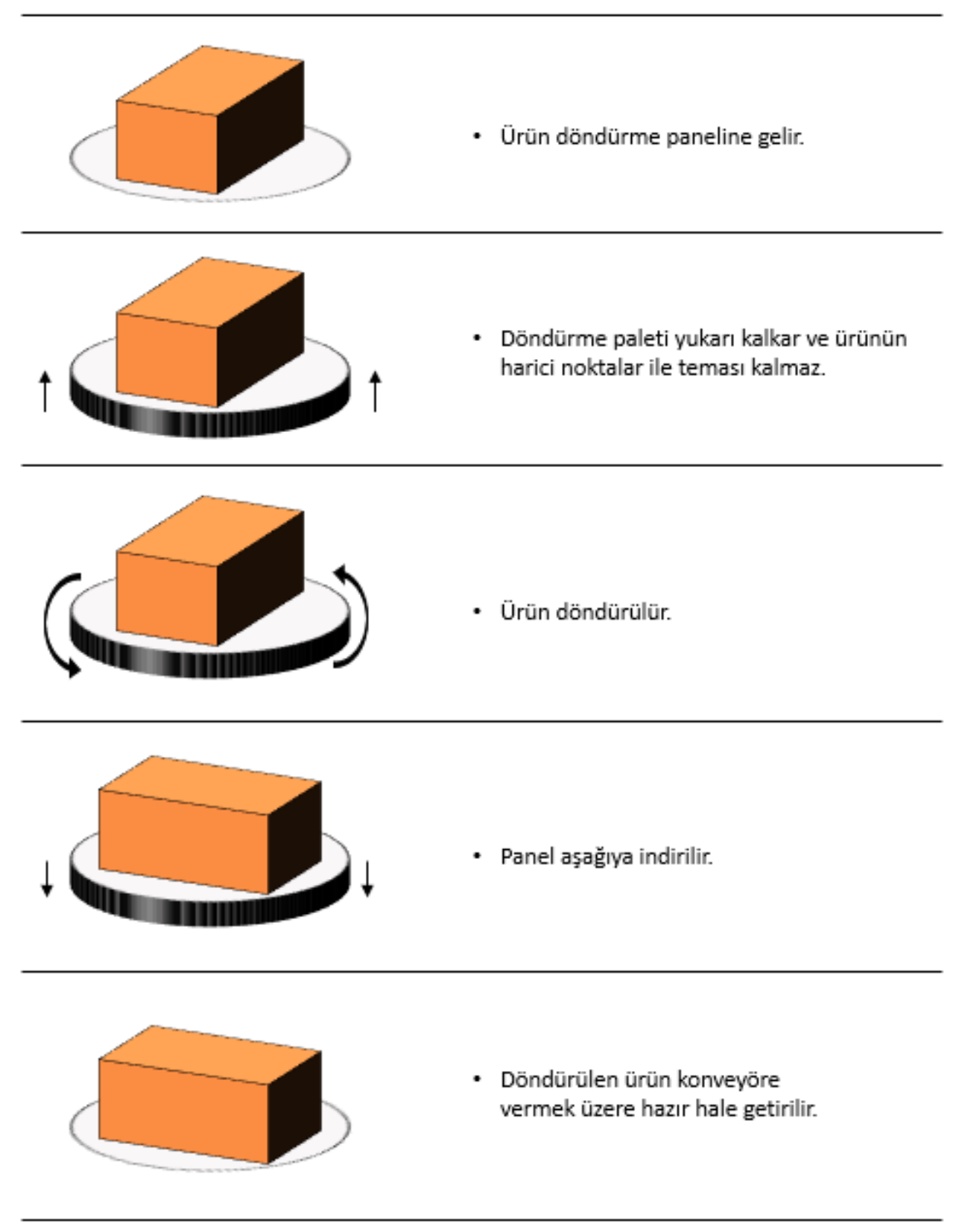

Şekil 4. Döndürme panelinin çalı̧̧ma mantığ1

\subsection{Kartezyen Taşıma Robotları}

Taşıma robotlarının ürünleri üzerine alıp sabitleyebilmesi için mengene kolları tasarlanmıştır. Mengene kolları elektriksek motorlar ile çalışmaktadır. Ürünleri sıkıştırırken gerekli sıkma miktarı, ürün ebat ölçümü sırasında elde edilmiştir. Sıkıştırılıp sabitlenen ürünler, taşıma robotunun yatay ve dikey hareket kabiliyeti ile belirlenen raf hücresine götürülür ve yüklenir [7]. 


\subsection{Raf Yapılart}

Raflara yüklenen ürün ebatlarına göre raflar farklılık göstermektedir. Standart ebatlar için tasarlanan ODBS sistemlerinde tüm raflar aynı ebattadır. Rafların aynı ebatta olması rafların üretilmesi ve montajı sırasında maliyet noktasında ciddi kazançlar sağlamaktadır. Bunun yanında bu bildiri çalışması kapsamında geliştirilen ODBS sistemi, farklı ebattaki kutuların depolanabilmesi için tasarlanmıştır. Ürün ebatlarındaki farklılıklardan dolayı her raf hücresinin aynı olması mekan açısından verimsiz bir durum oluşturmaktadır. Verimli ve esnek bir raf modeli oluşturmak için 6 farklı hücre modeli oluşturulmuştur. Tasarlanan raf modeli minimum $100 \times 100 \times 100 \mathrm{~mm}$ ve maksimum $500 \times 500 \times 500 \mathrm{~mm}$ ebat sınırları içerisinde gelen tüm ürünleri kabul etmektedir. Raf modeli Şekil 5 'te gösterilmiştir.

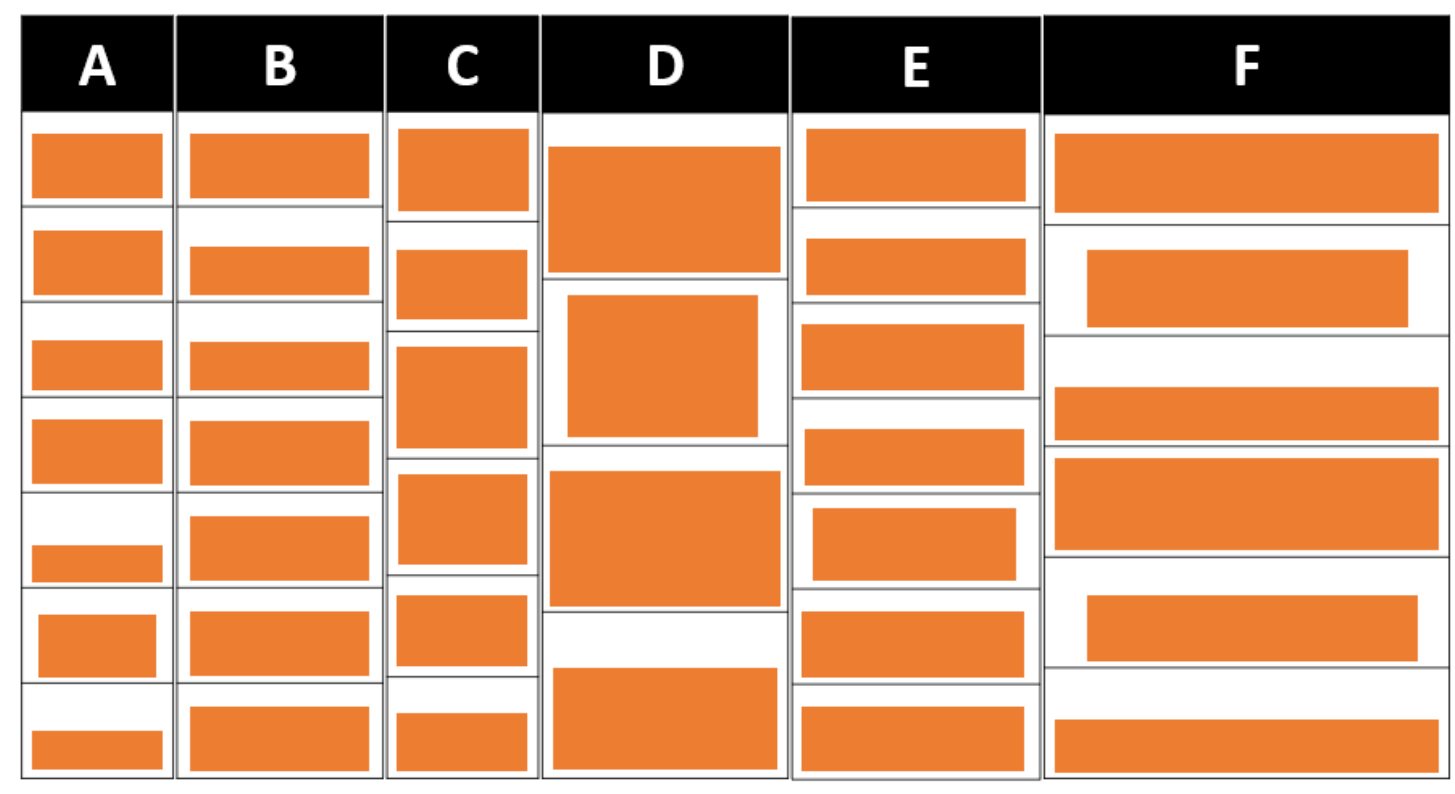

Şekil 5. Farklı ebatlı raf modeli (önden görünüş)

Tasarlanan raf modeli ile sınırlar dahilinde sisteme giren her ürün için altı hücre tipinden biri seçilmektedir. Raf hücreleri 2000mm uzunluğunda tasarlanmıştır. Böylece birden fazla ürün arka arkaya dizilebilmektedir.

Raflara yüklenen ürünlerin yerçekimi etkisi ile hücrelerin son noktalarına ilerlemeleri amacıyla raflara altı derecelik bir açı ile eğim verilmiştir. Ürünlerin kaymalarını kolaylaştırmak amacıyla hücrelerin tabanlarına serbest dönebilen makaralar yerleştirilmiştir. Boşaltma robotu hücredeki son ürünü aldığında arkadaki ürünler son noktaya doğru kaymaktadır. Tasarlanan ve uygulaması yapılan raf modelinin yapısı Şekil 6'da gösterilmiştir. 


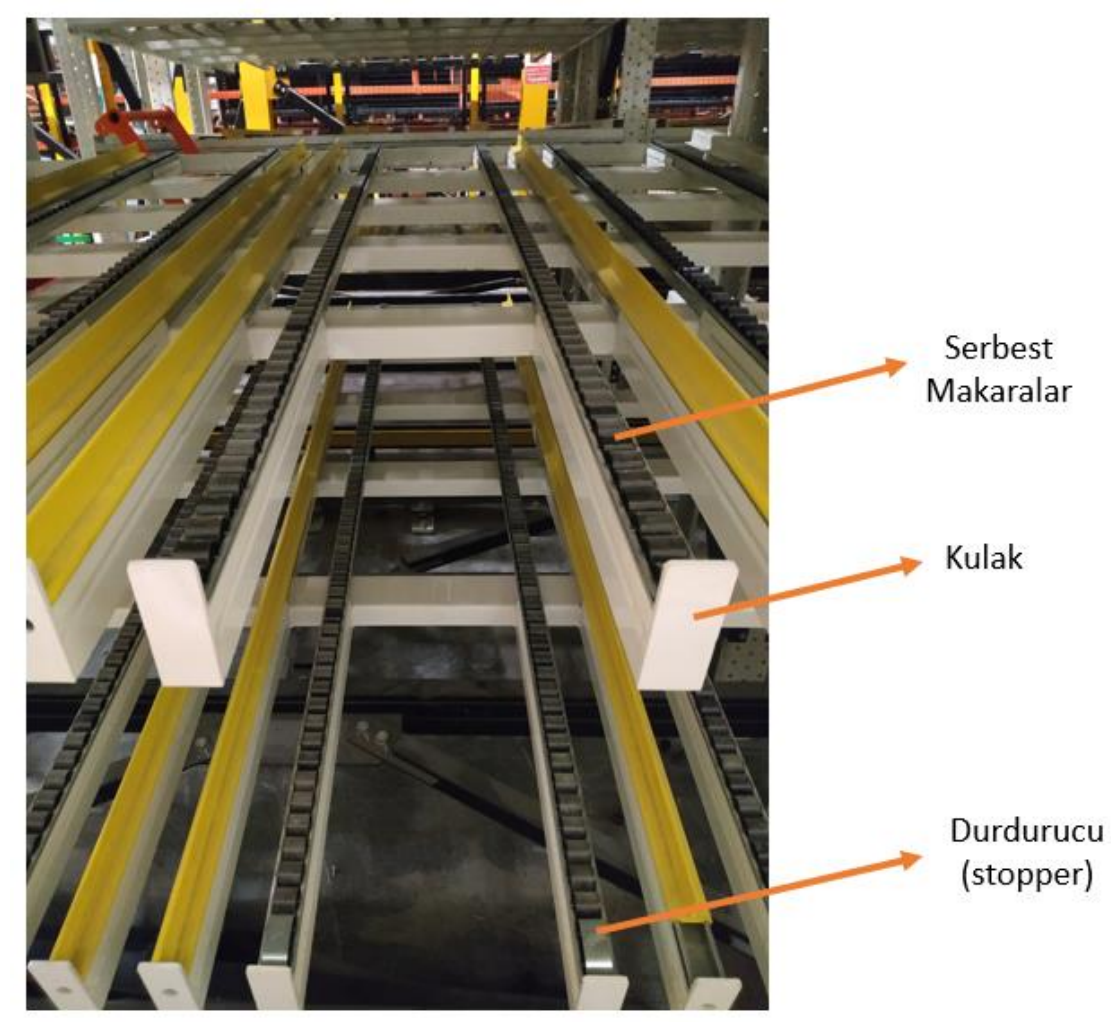

Şekil 6. Eğimli raf modeli uygulaması

Ürünlerin hücrede ilerlerken son noktaya geldiklerinde yavaşlamaları için durdurucu (stopper) aparatları yerleştirilmiştir. Ürünlerin son noktada kesin ve belirli bir noktada durmalarını sağlamak amacı ile kulakçık denilen ve çelikten üretilen sağlam yapılar tasarlanmış, üretilmiş ve uygulanmıştır.

\subsection{Kartezyen Boşaltma Robotları}

Hücrelerin son noktalarını gelen ürünler boşaltma robotları tarafından forklift kollarına benzeyen bir yapı ile alınıp çıkış bölgesine götürülmektedir [8]. Tasarlanan her raf hücresinin son noktasında iki adet kulak bulunmaktadır. Boşaltma robotları hücredeki ürünün genişlik bilgisine göre forklift kolunu, ürünü dengeli bir şekilde taşıyacak kadar açmaktadır. Boşaltma robotu kollar ile ürünün altına girip ürünü geri çekerken kulaklara çarpmayacak kadar (40 mm ile $60 \mathrm{~mm}$ arasında) yükseltmektedir. Boşaltma robotunun ürünleri raf hücrelerinden alma mantığı Şekil 7'de gösterilmiştir. 

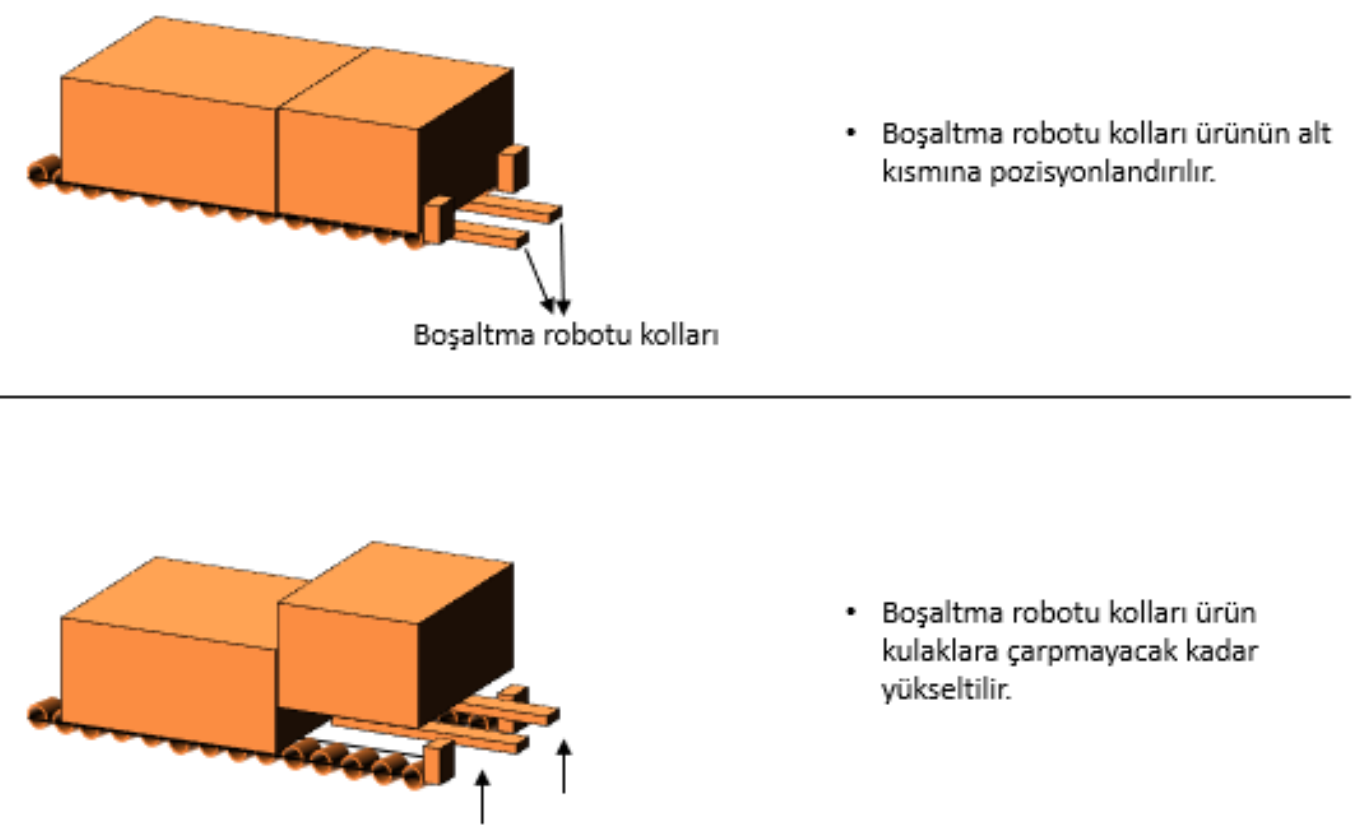

- Boşaltma robotu kolları ürün kulaklara çarpmayacak kadar yükseltilir.

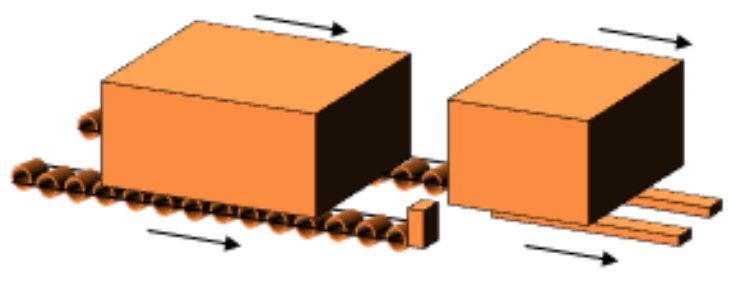

- Boşaltma robotu kolları geri çeker ve ürünü raftan alma işlemi tamamlanmış olur.

- Arkada bulunan ürünler son noktaya doğru ilerler.

Şekil 7. Boşaltma robotunun ürünleri alma mantığı

\section{Sonuç ve Değerlendirme}

Tasarlanan çok derinlikli ve farklı ebatlardaki ürünleri alabilir ODBS sisteminin tasarımı yapılmış ve bir endüstriyel firmada uygulanmıştır. Uygulama sonucu yapılan çalışmanın operatör eliyle ve forklift aracı ile yapılan depolama yöntemlerine göre çok daha verimli olduğu görülmüştür. Verimlilik analizleri yapılırken depolama için gerekli alan, depolama süresi, yanlış depolama ve ürün kaybolması gibi parametrelere dikkat edilmiştir. 
Sisteme giriş yapacak bir kısım ürünlerin sisteme yüklenmeden önce taşınırken zarar gördüğü görülmüştür. Zarar gören ürünlerin üzerlerinde kağıt ve benzeri parçaların serbest bir şekilde durduğu ve bu parçaların ebat ölçüm paneline yanılttığı görülmüştür. Bu küçük parçalardan etkilenmeyen bir ebat ölçüm paneli yapmak adına fiziksel bir ölçüm panelinin yapılmasının daha kullanışı olacağı anlaşılmıştır. Böylece kağıt ve bant gibi parçaların fiziksel bir yapıyla bastırılarak etkilerinin ortadan kalkması ve ebat ölçümünü yanıltmaması sağlanabilir.

Yapılan çalışmada ürün döndürme paneli pnömatik yapılar ile tasarlanmış ve hassas kontrol sağlanamadığı görülmüştür. Kırılabilir ürünlerin depolanacağı sektörler için döndürme panellerinin elektrikli motorlar kullanılarak daha hassas bir şekilde yapılmasının uygun olacağı anlaşılmıştır.

\section{Kaynaklar}

[1] Soyaslan, M. (2012). "Sıvı Gıda Üretim Sektörü için Robotik Tabanlı Akıllı Depolama Sistemlerinin Otomasyonu” Yüksek Lisans Tezi, Gaziosmanpaşa Üniversitesi.

[2] www.ignou.ac.in/upload/Unit4-55.pdf.

[3] Soyaslan, M., Fenercioğlu, A. \& Közkurt, C. (2012) "An Approach of Control System for Automated Storage and Retrieval System (AS/RS)." Proceedings of World Academy of Science, Engineering and Technology. No. 69. World Academy of Science, Engineering and Technology.

[4] Atmaca, E., \& Öztürk, A. (2014). Literatür Araştırması: Sipariş Toplama Politikaları ve Otomatik Depolama ve Boşaltma Sistemleri (AS/RS). Nevşehir Bilim ve Teknoloji Dergisi, 2(2).

[5] Kletti, J. 2006. MES - Manufacturing Execution System: Moderne Informations technologie zur Prozessfähigkeit der Wertschöpfung. Springer-Verlag, Berlin/Heidelberg, Germany.

[6] Pauker, F.; Ayatollahi, I.; Kittl, B. OPC UA for machine tending industrial robots. In Proceedings of the 2nd International Conference on Advances in Mechanical and Robotics Engineering (AMRE), Zurich, Switzerland, 25-26 October 2014.

[7] Malmborg, C.J., (2002). Conceptualizing tools for autonomous vehicle storage and retrieval systems. Int. Journal of Production Research 40 (8), 1807-1822.

[8] Yu, Y. and Koster, M.B.M., (2009). Designing an optimal turnover-based storage rack for a 3D compact automated storage and retrieval system. International Journal of Production Research, 47:6, 1551-1571 